\title{
A wedge is still a cancer operation, so treat it like one!
}

\author{
Seth B. Krantz, MD
}

\author{
From the Division of Thoracic Surgery, NorthShore University HealthSystem, Evanston, Ill; and Department of \\ Surgery, The University of Chicago Pritzker School of Medicine, Chicago, Ill. \\ Disclosures: Author has nothing to disclose with regard to commercial support. \\ Received for publication April 16, 2018; accepted for publication April 17, 2018; available ahead of print May 15 , \\ 2018. \\ Address for reprints: Seth B. Krantz, MD, NorthShore University HealthSystem, 2650 Ridge Ave, Walgreen Suite \\ 3507, Evanston, IL 60201 (E-mail: skrantz@northshore.org). \\ J Thorac Cardiovasc Surg 2018; 156:403 \\ $0022-5223 / \$ 36.00$ \\ Copyright (c) 2018 by The American Association for Thoracic Surgery \\ https://doi.org/10.1016/j.jtcvs.2018.04.081
}

The important article by Yendamuri and colleagues, "Impact of the Number of Lymph Nodes Examined on the Survival of Patients with Stage I Non-Small Cell Lung Cancer Undergoing Sublobar Resection," adds to the growing body of literature demonstrating 2 important facts: (1) A sublobar resection, specifically a wedge resection, is a reasonable cancer operation in patients not fit for lobectomy; and (2) treating it like a cancer operation, with adequate lymph node evaluation, is an essential part of the operation and has a strong association with good patient outcomes. In their analysis of approximately 4000 patients with small $(<2 \mathrm{~cm})$, stage I non-small cell lung cancer who underwent wedge resection $(82 \%)$ or segmentectomy $(18 \%)$, they showed that improved overall and diseasespecific survival were strongly associated with increased lymph node assessment. Furthermore, the benefit for anatomic segmentectomy over wedge resection found in univariate analysis was not seen in patients who had at least 1 lymph node assessed during their wedge resection.

This article complements other articles also demonstrating the importance of lymph node assessment in wedge resection. Sadly, their article also confirms the overall lack of good lymph node assessment occurring in patients receiving wedge resection for early-stage lung cancer. In their analysis, more than $50 \%$ of patients receiving wedge resection had 0 lymph nodes assessed and only $25 \%$ had more than 4 nodes assessed. For patients receiving segmentectomy, approximately $25 \%$ had no lymph nodes assessed. This is consistent with subgroup analysis of the American College of Surgeons Oncology Group Z4032. ${ }^{2}$ Work recently published in the Journal by our group looked at a similar population within the National Cancer Database. ${ }^{3}$ In that cohort, $44 \%$ had no lymph nodes assessed. Similar to the results in the current study, our study found that improved lymph node assessment was associated with a significant improvement in overall survival. By comparing these 2 studies, they offer a complementary picture of the role of sublobar resection and adequate lymph node assessment. In the current analysis, Yendamuri and colleagues ${ }^{1}$ were able to show improvements in both disease-specific

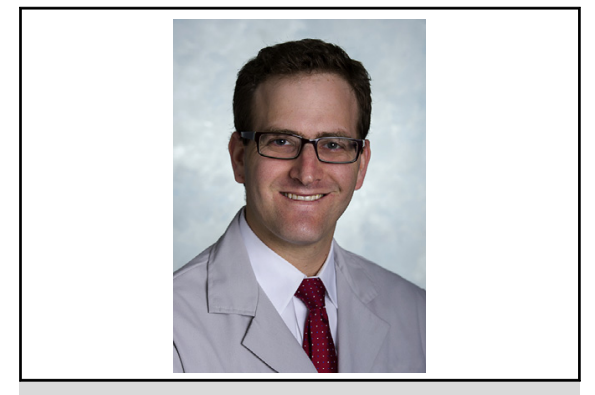

Seth B. Krantz, MD

Central Message

Sublobar resection is a viable alternative in patients not fit for lobectomy. More thorough lymph node sampling is associated with superior disease-specific and overall survival.

See Article page 394.

survival and overall survival. Furthermore, by including only patients with tumors less than $2 \mathrm{~cm}$, they show the benefit even in very small early-stage tumors. One limitation is the inability to assess upstaging and the inability to assess adjuvant chemotherapy use. In our analysis of the National Cancer Database, we found an upstaging rate of $5 \%$ for patients with lymph nodes assessed and $8 \%$ for patients who had at least 10 nodes assessed. Furthermore, of those with positive nodes, approximately $65 \%$ were offered adjuvant chemotherapy.

Additional limitations not withstanding, this article shows that for small tumors $(<2 \mathrm{~cm})$, nonanatomic resection and segmentectomy are associated with equally good cancer-specific and overall survival, so long as lymph nodes are assessed. Furthermore, increased assessment of lymph nodes shows a strong linear association with improved outcomes. If we as a thoracic community are going to offer sublobar resection as a viable cancer operation, it behooves us to treat it like one and take the time and effort to assess as many lymph node stations as possible.

\section{References}

1. Yendamuri S, Dhillon SS, Groman A, Dy G, Dexter E, Picone A, et al. Impact of the number of lymph nodes examined on the survival of patients with stage I nonsmall cell lung cancer undergoing sublobar resection. J Thorac Cardiovasc Surg. 2018;156:394-402.

2. Kent M, Landreneau R, Mandrekar S, Hillman S, Nichols F, Jones D, et al. Segmentectomy versus wedge resection for non-small cell lung cancer in high-risk operable patients. Ann Thorac Surg. 2013;96:1747-55.

3. Ajmani GS, Wang C, Kim K, Howington JA, Krantz SB. Surgical quality of wedge resection affects overall survival in patients with early stage non-small cell lung cancer. J Thorac Cardiovasc Surg. March 13, 2018 [Epub ahead of print]. 